\title{
Low-pressure pneumoperitoneum reduces influence on ovarian hormones in infertile women: a randomised trial
}

\author{
Juan Qin ${ }^{1 *}$, Guoling Song ${ }^{2 \#}$, Yao Jiang ${ }^{1}$, Qin Liu ${ }^{1}$, Hong Lin ${ }^{1}$ \\ ${ }^{1}$ Department of Obstetrics and Gynecology, The Maternal and Child Health Care Hospital of Guizhou Medical University, Guiyang, China; \\ ${ }^{2}$ Emergency department, Guizhou University of traditional Chinese Medicine, Guiyang, China \\ Contributions: (I) Conception and design: J Qin, G Song; (II) Administrative support: J Qin; (III) Provision of study materials or participants: J Qin, \\ G Song, Q Liu; (IV) Collection and assembly of data: G Song, Y Jiang; (V) Data analysis and interpretation: J Qin, G Song; (VI) Manuscript writing: \\ All authors; (VII) Final approval of manuscript: All authors. \\ \#The authors contributed equally to this work. \\ Correspondence to: Juan Qin. Department of Obstetrics and Gynecology, Guiyang Maternal and Child Health Care Hospital, Guizhou Medical \\ University, 63 Ruijin South Road, Guiyang 560000, China. Email: qinjuangzykdx@163.com.
}

\begin{abstract}
Background Pneumoperitoneum is commonly used in laparoscopic gynecological surgery. This study investigated the effect of carbon dioxide $\left(\mathrm{CO}_{2}\right)$ pneumoperitoneum pressure on ovarian function following laparoscopic surgery in infertile women.

Methods: A total of 424 infertile patients were allocated to 4 groups according to different $\mathrm{CO}_{2}$ pneumoperitoneum pressures undergo laparoscopic surgery. Complications and the levels of serum estradiol $\left(\mathrm{E}_{2}\right)$, progesterone $(\mathrm{P})$, luteinizing hormone $(\mathrm{LH})$, testosterone $(\mathrm{T})$, and follicle-stimulating hormone $(\mathrm{FSH})$ were observed and measured. Ovarian function was also evaluated by using mean ovarian volume, maximal ovarian volume, mean follicle number, and maximal follicle diameter.
\end{abstract}

Results: A total of 118 cases were included and their data were retrospectively analyzed. Complications were observed in all groups with the highest incidence in participants receiving $15-16 \mathrm{mmHg} \mathrm{CO}_{2}$. Pneumoperitoneum increased the levels of $\mathrm{E}_{2}, \mathrm{FSH}$, and $\mathrm{LH}(\mathrm{P}<0.05)$ with increasing pressure, especially in the first menstrual period after surgery, and these levels had returned to normal by the third menstruation; the levels of $\mathrm{P}$ and $\mathrm{T}$ were not affected.The MOV, MFD and MFN remained unchanged after surgery in four groups, and the menstrual cycle after surgery at 1 month in group $\mathrm{D}$ delayed $(\mathrm{P}<0.05)$.

Conclusions: The use of $\mathrm{CO}_{2}$ for pneumoperitoneum affects the levels of $\mathrm{E}_{2}, \mathrm{LH}$, and FSH during the first menstruation after laparoscopic surgery in a pressure-dependent manner and the impact vanishes by the third menstruation.

Trial Registration: Chinese Clinical Trial Registry ChiCTR2100046221.

Keywords: Carbon dioxide $\left(\mathrm{CO}_{2}\right)$; pneumoperitoneum; laparoscopic surgery; ovarian hormones

Submitted Dec 30, 2020. Accepted for publication Apr 24, 2021.

doi: $10.21037 /$ apm-21-476

View this article at: http://dx.doi.org/10.21037/apm-21-476

\section{Introduction}

In recent years, laparoscopic surgery has become one of the most important diagnostic and therapeutic approaches in gynecological surgery. The surgery can improve the efficiency and maintain hemodynamic stability in laparoscopy for gynecological diseases (1). This minimally invasive therapy requires pneumoperitoneum for adequate visualization and operative manipulation. Carbon dioxide $\left(\mathrm{CO}_{2}\right)$ is the most commonly used gas to inflate the peritoneum, because of its high diffusibility and rapid absorption and excretion. Compared with open surgical procedures, this technique potentially offers shorter operative time and hospital stay, earlier recovery, and less pain and pelvic adhesions $(2,3)$. 


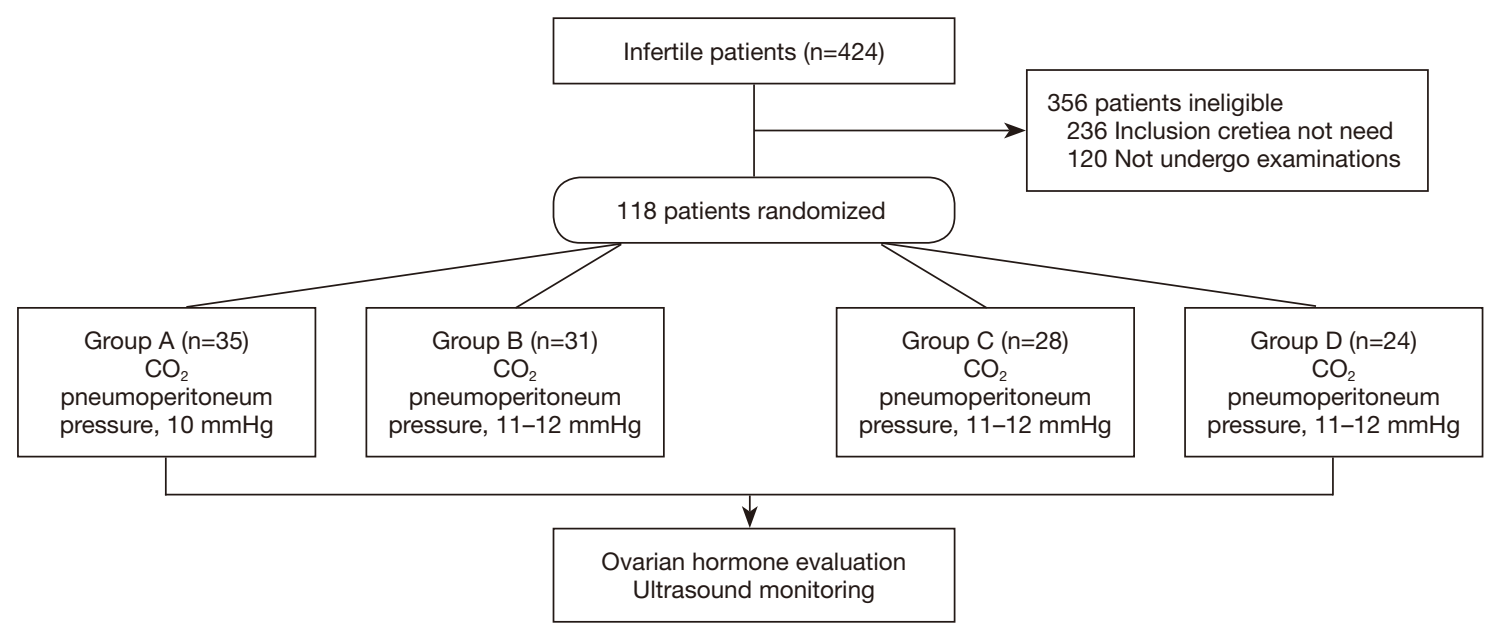

Figure 1 Study profile.

However, insufflation of $\mathrm{CO}_{2}$ into the peritoneum may lead to alterations in the acid-base balance, and cardiovascular and pulmonary physiology. Mastroyannis et al. reported the effects of $\mathrm{CO}_{2}$ pneumoperitoneum pressure on rabbit follicular oocytes and early embryonic development using the animal model of pneumoperitoneum. They found that the duration of pneumoperitoneum, irrespective of type of gas used, was negatively correlated with success of embryonic development (4).

There are many reports on the safety of low $\mathrm{CO}_{2}$ pneumoperitoneum pressure $(5,6)$. The benefits of laparoscopic surgery include reduced blood loss, fewer transfusions, and shorter hospital stay. Peng et al. found that $\mathrm{CO}_{2}$ pneumoperitoneum did not raise the incidence rate of bacterial translocation under laparoscopy surgery (7). Chen et al. showed that $\mathrm{CO}_{2}$ pneumoperitoneum did not affect expression of the cellular proliferation marker Ki67 in an orthotropic xenograft nude mouse model of human renal cell carcinoma (8). Contrastingly, high pressure $\mathrm{CO}_{2}$ pneumoperitoneum was found to induce oxidative damage and apoptosis in rabbit kidneys with severe hydronephrosis (9). However, there has been little exploration of the clinical effects of low $\mathrm{CO}_{2}$ pneumoperitoneum pressure in post obstetric surgery patients. Akdemir et al. demonstrated that $\mathrm{CO}_{2}$ pneumoperitoneum does not cause ischemia-reperfusion injury in premenopausal human ovaries at clinically safe levels of intra-abdominal pressure $(14 \mathrm{mmHg})(10)$. However, the effect of different $\mathrm{CO}_{2}$ pneumoperitoneum pressure on ovarian function in laparoscopy has not been reported. Therefore, it is very important for gynecologists to fathom the effect of pneumoperitoneum pressure on reproductive-age patients.

The purpose of our study was to evaluate the effect of $\mathrm{CO}_{2}$ pneumoperitoneum pressure on ovarian hormones in infertile women. The findings were intended to contribute to the development of a standard of $\mathrm{CO}_{2}$ pneumoperitoneum pressure for infertile women undergoing laparoscopic surgery and reduce the adverse effects of the surgery.

We present the following article in accordance with the CONSORT reporting checklist (available at http://dx.doi. org/10.21037/apm-21-476).

\section{Methods}

\section{Participants}

From April 2009 to May 2013, a total of 424 women diagnosed infertile at the Institute of Obstetrics and Gynecology were screened for this study (Figure 1). Patients were included if their infertility was caused by pelvic adhesions, tubal factors, or unexplained, and were followed up for 3 menstrual cycles following surgery.

Patients with endocrine-related diseases, such as endometriosis and polycystic ovary syndrome (PCOS), were excluded. Participants who dropped out during the course of study were also excluded. The excluded cases were as follows: 106 were diagnosed with endometriosis upon surgery; 80 were diagnosed with PCOS, 50 had ovarian cysts detected during surgery (ovarian endometrial cyst, 26 cases; teratoma, 18 cases; corpus luteum cyst, 6 cases). A total of 120 cases were excluded who did not undergo blood 
Table1 Baseline characteristics of the study sample

\begin{tabular}{|c|c|c|c|c|}
\hline Characteristic & Group A $(n=35)$ & Group B (n=31) & Group C (n=28) & Group D $(n=24)$ \\
\hline Body mass index $\left(\mathrm{kg} / \mathrm{m}^{2}\right)$ & $21.27 \pm 2.36$ & $21.89 \pm 2.45$ & $22.36 \pm 2.09$ & A $21.85 \pm 2.05$ \\
\hline Surgical time (minutes) & $60.34 \pm 15.33$ & $62.1 \pm 16.71$ & $62.69 \pm 18$ & $94.55 \pm 11.7^{\mathrm{a}}$ \\
\hline Hospital days (days) & $4.17 \pm 0.77$ & $4.37 \pm 0.81$ & $4.19 \pm 0.76$ & $4.95 \pm 0.58$ \\
\hline Inoperative adhesion (\%) & 11.4 & 19.3 & 17.9 & $37.5^{\mathrm{a}}$ \\
\hline
\end{tabular}

${ }^{\mathrm{a}}, \mathrm{P}<0.05$ vs. group $\mathrm{A}, \mathrm{B}$, and $\mathrm{C}$.

draw or ultrasound examination.

A total of 118 patients (aged 18-39 years) met the inclusion criteria and were retrospectively analyzed. Among them, 70 participants underwent laparoscopic surgery for pelvic adhesions, 20 underwent tubal colostomy, 6 underwent tubal fimbria angioplasty, and 22 underwent laparoscopic surgery for detection. According to the $\mathrm{CO}_{2}$ pressure applied in laparoscopic surgery, and the volume of insufflation of $\mathrm{CO}_{2}$ was determined by pneumoperitoneum pressure indicator (Olympus UHI-4; Japan), participants were divided into 4 groups [A, $10 \mathrm{mmHg}(\mathrm{n}=35), B$, 11-12 mmHg $(\mathrm{n}=31), \mathrm{C}, 13-14 \mathrm{mmHg}(\mathrm{n}=28)$, and $\mathrm{D}$, $15-16 \mathrm{mmHg}(\mathrm{n}=24)$, respectively] (Figure 1). All surgical procedures were performed by the same surgeons. Written informed consent was provided by every participant and the study protocols were approved by the Ethics Committee and Institutional Review Board of the Maternal and Child Hospital (No. 81), Guiyang. All procedures performed in this study involving human participants were in accordance with the Declaration of Helsinki (as revised in 2013).

\section{Ovarian bormone evaluation}

The ovarian hormones estradiol $\left(\mathrm{E}_{2}\right)$, progesterone $(\mathrm{P})$, luteinizing hormone $(\mathrm{LH})$, testosterone $(\mathrm{T})$, and follicle-stimulating hormone (FSH) were detected by radioimmunoassay. These hormones were assessed before and on days 3 and 5 of the first and third menstrual cycles after surgery.

\section{Ultrasound monitoring}

Uterus and bilateral annexes were detected via vaginal examination on the first 3-5 days of menstruation before and after surgery. A $6.0 \mathrm{MHz}$ vaginal probe of B-mode ultrasound (Sonolayer SSA-220A, Toshiba, Tokyo, Japan) was used for examination. The number and diameter of follicles and diameter of ovaries were measured at 3 time points (T0, before operation; T1, 1 month after operation; T2, 3 months after operation). Ovarian volume was calculated as previously described (11). Ovarian function was also evaluated using mean ovarian volume (MOV, the average volume of both ovaries), maximal ovarian volume (MaxOV, the volume of the largest ovary), mean follicle number (MFN, the mean number of bilateral ovarian follicles), and maximal follicle diameter (MFD, the dominant follicle diameter).

\section{Statistical methods}

Measurements were expressed as means \pm SD and/ or median and range. Means were compared using the Student's $t$-test or 2-way analysis of variance (ANOVA) with the corresponding post-test. All statistical tests were 2-tailed and $\mathrm{P}$ value $<0.05$ was considered statistically significant. All data were analyzed using the software SPSS 19.0 (SPSS, Inc., IBM, Chicago, IL, USA).

\section{Results}

\section{Participants and surgical complications}

A total of 118 patients were included in this study. The mean age of the participants was $27.2 \pm 4.6$ years $(18$ 36 years). The mean surgery time was $89 \pm 16$ min ( $35-$ $120 \mathrm{~min})$. The total numbers of participants were 35,31 , 28 , and 24 in groups A, B, C, and D, respectively. Length of hospital stay was not different among the 4 groups $(\mathrm{P}>0.05)$. Group D had the longest surgical time, and also had the highest frequency of pelvic adhesion $(37.5 \%$, Table 1$)$. 
Table 2 Surgery related complications in four groups

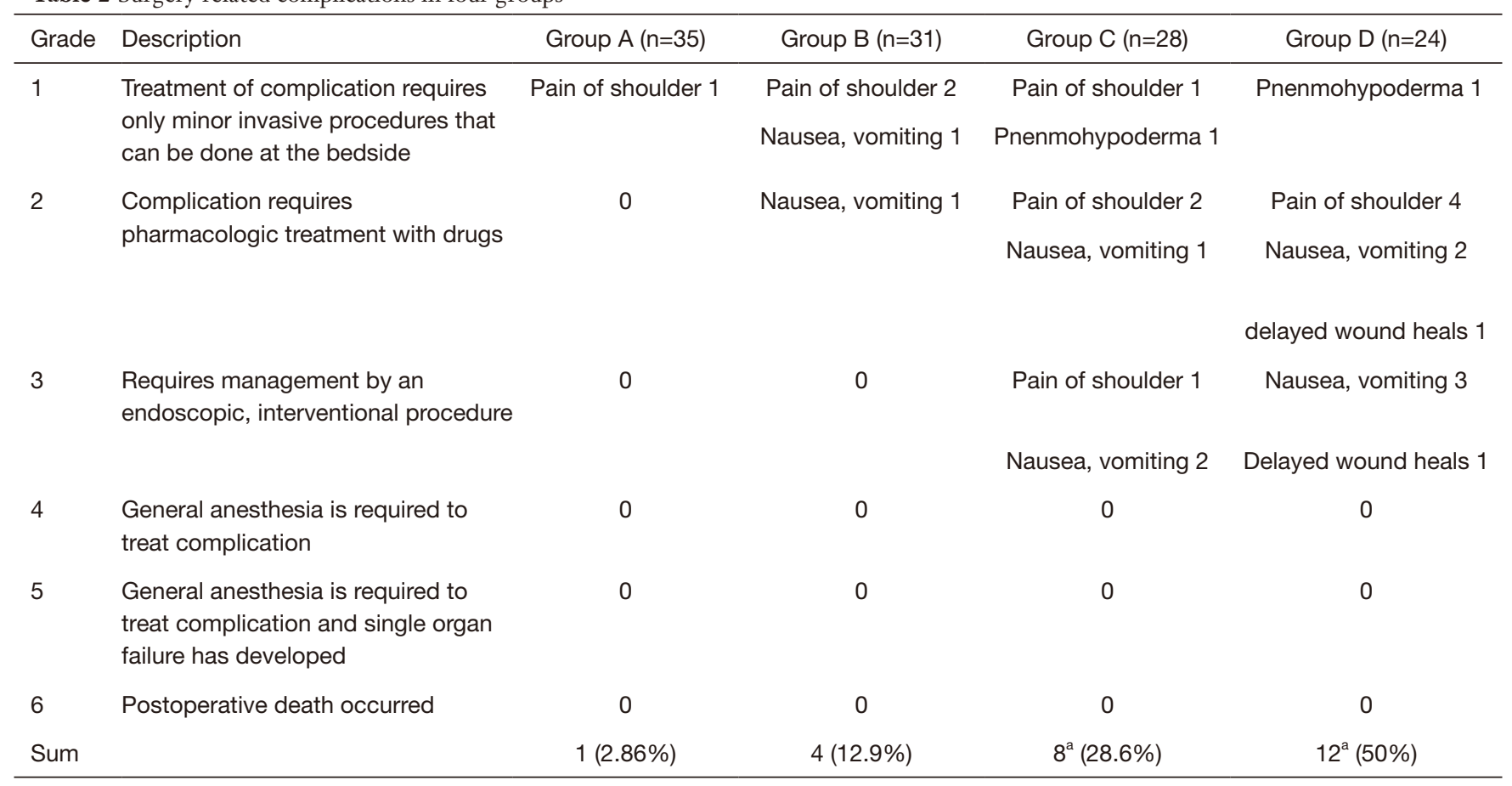

${ }^{\mathrm{a}}, \mathrm{P}<0.05$, vs. group $\mathrm{A}$.

Surgical complications were graded according to the Accordion Severity Grading System (12) and the results are summarized in Table 2, including pneumohypoderma, shoulder pain, delayed wound healing, and postoperative nausea and vomiting. The incidences of complications in group A, B, C, and D were $2.86 \%, 12.9 \%, 28.6 \%$, and $50 \%$, respectively, and were significantly higher in group $\mathrm{C}$ and $\mathrm{D}$ than in group $\mathrm{A}(\mathrm{P}<0.05)$. No severe complications were observed in all groups, such as severe infection or damage to adjacent organs and blood vessels.

\section{Ovarian hormones $E_{2}, F S H, L H, P$, and T}

Preoperative levels of ovarian hormones were within the normal range and were similar among the 4 groups. The $\mathrm{E}_{2}$ decreased significantly in the first menstrual period following surgery as compared with before surgery $(\mathrm{P}<0.05)$ and returned to the preoperative levels in the third menstrual period (Figure $2 A$ ). It trended to decrease with increasing $\mathrm{CO}_{2}$ pressure. After surgery, serum $\mathrm{E}_{2}$ was the lowest in group D, although it was not significantly different among the 4 groups ( $\mathrm{P}>0.05$, Figure $2 A)$.

Levels of LH and FSH were higher at the first menstrual period after surgery than before surgery $(\mathrm{P}<0.05)$. Both had returned to normal range at the third menstrual period (Figure 2B,C). The concentrations of $\mathrm{LH}$ and $\mathrm{FSH}$ showed an increasing tendency with increasing $\mathrm{CO}_{2}$ pressure, especially in group $\mathrm{D}$, where they were statistically higher than in the other 3 groups $(\mathrm{P}<0.05)$ (Figure $2 B, C)$. The levels of $\mathrm{P}$ and $\mathrm{T}$ did not show significant change after surgery and $\mathrm{CO}_{2}$ pressure did not affect the levels of these hormones $(\mathrm{P}>0.05$, Figure 2D,E).

\section{MOV, MFN, and MFD}

We then surveyed the change of ovarian structures with B-mode ultrasound at day 5 of the menstrual cycle. The MOV, MFD, and MFN remained unchanged after surgery (Figure $3 A, B, C, \mathrm{P}>0.05$ ), although $\mathrm{MFN}$ in group $\mathrm{D}$ showed a statistically insignificant decrease at 1 month $(\mathrm{P}>0.05$, Figure 3C).

\section{Length of menstrual cycle}

We followed up the menstrual cycle after surgery and found that the menstrual period of participants in group $\mathrm{D}$ were delayed at 1 month post operation $(\mathrm{P}<0.05$, Figure $3 D)$. However, it had recovered to normal range at the third 


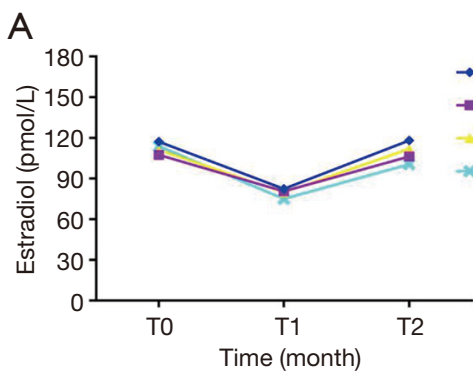

B

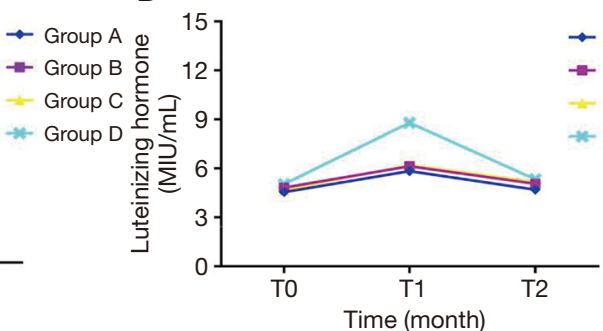

$\mathrm{E}$

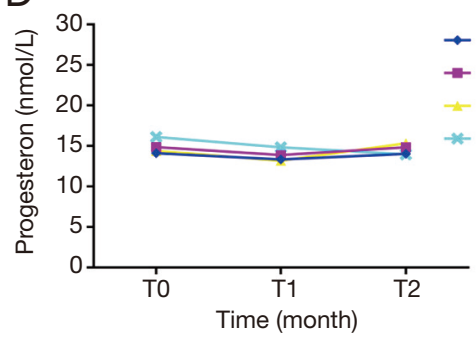

C

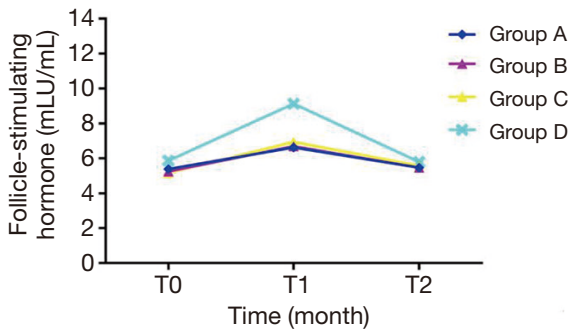

Figure 2 The levels of ovarian hormones before and after surgery under different $\mathrm{CO}_{2}$ pneumoperitoneum pressures. (A) Estradiol; (B) luteinizing hormone; (C) follicle-stimulating hormone; (D) progesterone; and (E) testosterone. T0, before operation; T1-2, one and three months after operation. $\mathrm{CO}_{2}$, carbon dioxide.
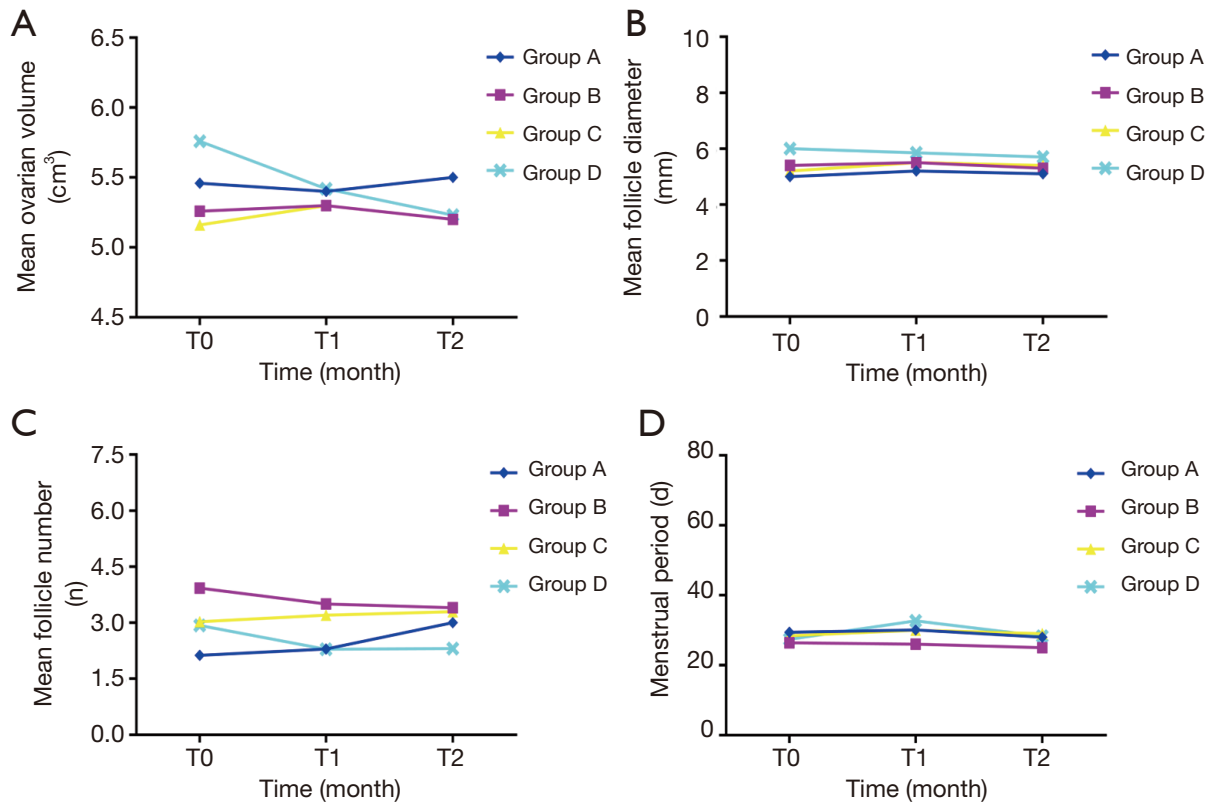

Figure 3 The MOV, MFN, MFD, and menstrual period before and after surgery under different carbon dioxide pneumoperitoneum pressures. (A) Mean ovarian volume; (B) mean follicle diameter; (C) mean follicle number; (D) menstrual period (day). T0, before operation; T1-2, 1 or 3 months after operation. MOV, mean ovarian volume; MFN, mean follicle diameter; MFD, mean follicle diameter. 
menstrual period. Within 1 year, 46 participants were successfully pregnant after surgery.

\section{Discussion}

Increased intra-abdominal pressure used in laparoscopy resulting from pneumoperitoneum may lead to systemic effects, such as acid-base imbalance, blood gas alterations, and pulmonary disease, cardiovascular disease, pneumothorax, mediastinal emphysema, air embolism, and acute respiratory distress syndrome (ARDS) $(13,14)$. We reviewed the literature for clinical and laboratory studies on the currently used laparoscopic insufflation gases, and $\mathrm{CO}_{2}$ showed adverse effects on respiration and circulation (15).

Eleftheriadis et al. found when pneumoperitoneum pressure was up to $15 \mathrm{mmHg}$, bacteria could diffuse to other organs in the abdominal cavity (16). Marana et al. confirmed that $\mathrm{CO}_{2}$ pneumoperitoneum pressure affected stressrelated neuroendocrine hormones after comparing the level of stress hormones, plasma epinephrine, norepinephrine, and epinephrine after laparoscopy, mini laparotomy, and laparotomy (17). However, the range of pneumoperitoneum pressure that is safe for ovarian function has not been well defined. Bogani et al. compared low (LPP $8 \mathrm{mmHg}$ ) vs. standard pneumoperitoneum pressure (SPP $12 \mathrm{mmHg}$ ) during mini-laparoscopic hysterectomy (MLH), and found there was less shoulder-tip pain in LPP (18). In our study, low $\mathrm{CO}_{2}$ pneumoperitoneum pressure was found to be safer and feasible for surgery. No severe complications, such as infection, adjacent organ damage, abdominal vascular injury, and drain off into the abdominals, occurred at low pressure. Conversely, under high pressure $(15-16 \mathrm{mmHg})$, more complications were observed, which was similar to earlier works (18).

Our analysis showed that $\mathrm{CO}_{2}$ pressure of $\mathrm{CO}_{2}$ has some effects on ovarian hormones, especially in the first postoperative menstrual period. When the pressure applied exceeded $15 \mathrm{mmHg}$, the serum $\mathrm{LH}$ and FSH increased significantly in the first menstrual period. At the highest pressure, patients' menstrual cycles were extended. Recently, a prospective study showed that $\mathrm{CO}_{2}$ pneumoperitoneum caused acute injury to the retained kidney after laparoscopic donor nephrectomy (19). Our data showed that Group D had the longest surgical time, and the highest incidence of pelvic adhesion (37.5\%). We speculate that high pressure may reduce ovarian blood supply during operation, and this adverse effect would prolong surgical time and increase surgical difficulty.
Meanwhile, we also found that increased pneumoperitoneum pressure might result in reduced follicle numbers. These clinical observations and laboratory data suggest that high pneumoperitoneum pressure may adversely affect follicular development during the cycle.

Measurement of FSH and LH during the cycle can reflect ovarian reserve (20). Based on the recent result that high $\mathrm{CO}_{2}$ pneumoperitoneum pressure reduced splanchnic blood $(19,21)$, it is likely that when $\mathrm{CO}_{2}$ pneumoperitoneum pressure exceeds $16 \mathrm{mmHg}$, it might affect the ovarian blood supply and cause a transient ischemia-reperfusion, affecting follicular development and leading to temporary follicular dysplasia. However, this impact is likely short-lived and would vanish soon after surgery. As a consequence, we observed that the ovarian hormone levels had returned to previous levels by the third menstrual period.

Previously, ovarian surgery was found to have various impacts on the menstrual cycle and ovarian function. For example, Sayegh et al. reported on 87 reproductive-aged women who had undergone pelvic surgery for indications including endometriosis, infertility, and pelvic pain; the result showed conservational ovarian surgery had no significant effects on ovulatory and menstrual function over a prolonged follow-up period (22). Zhang et al. found that ovarian biopsy/scratch could promote follicle development in vivo (23). In addition, surgical excision of endometriomas acutely impairs ovarian function (24) and hemostatic methods during surgery affect ovarian function (25).

We further analyzed the characteristics of participants in group D. Since frequent intraoperative adhesions occurred in the group, it is likely that the ovarian function affected by high $\mathrm{CO}_{2}$ pneumoperitoneum pressure resulted from the adhesions as well as from adhesion-induced release of inflammatory factors. Therefore, for patients with severe adhesions, factors other than pneumoperitoneum pressure should be taken into consideration. Based on our data, it is reasonable to interpret that $\mathrm{CO}_{2}$ pneumoperitoneum pressure below $16 \mathrm{mmHg}$ is safer for preservation of ovarian function. Base on the reported researches $(15,26)$, $\mathrm{N}_{2} \mathrm{O}$ (nitrous oxide) has only weak hemodynamic effects. It seems to be the alternative gas for insufflation into the peritoneum. Other gases such as helium, air, nitrogen and argon, which have no significant advantage over $\mathrm{CO}_{2}$ or $\mathrm{N}_{2} \mathrm{O}$. Menes T reviewed previous studies and concluded the effect of $\mathrm{CO}_{2}$ insufflation on acid-base changes usually are mild (15). 
However, further exploration is required on the impact of $\mathrm{CO}_{2}$ pneumoperitoneum pressure on acid-base changes and blood supplying the ovaries, oocyte quality, subsequent pregnancy in multi-center, large-cohort studies.

\section{Conclusions}

Our work demonstrated that low-pressure pneumoperitoneum in laparoscopic operation has less adverse impacts on ovarian function and a lower complication rate, suggesting that $\mathrm{CO}_{2}$ pressure below $16 \mathrm{mmHg}$ during laparoscopy for infertility patients is worthy of recommendation. However, this was a single center-, small-scale retrospective study, and the conclusions need to be validated in multi-center, large scale, and prospectively designed studies.

\section{Acknowledgments}

Funding: This study was supported by Guiyang Health Science and education foundation [2008] No.40.

\section{Footnote}

Trial Protocol: Available at http://dx.doi.org/10.21037/apm$21-476$

Reporting Checklist: The authors have completed the CONSORT reporting checklist. Available at http://dx.doi. org/10.21037/apm-21-476

Data Sharing Statement: Available at http://dx.doi. org/10.21037/apm-21-476

Conflicts of Interest: All authors have completed the ICMJE uniform disclosure form (available at http://dx.doi. org/10.21037/apm-21-476). The authors have no conflicts of interest to declare.

Ethical Statement: The authors are accountable for all aspects of the work in ensuring that questions related to the accuracy or integrity of any part of the work are appropriately investigated and resolved. This study was approved by the Ethics Committee and Institutional Review Board of Maternal and Child Hospital (No. 81), Guiyang and written consent was provided by every participant. All procedures performed in this study involving human participants were in accordance with the Declaration of Helsinki (as revised in 2013).
Open Access Statement: This is an Open Access article distributed in accordance with the Creative Commons Attribution-NonCommercial-NoDerivs 4.0 International License (CC BY-NC-ND 4.0), which permits the noncommercial replication and distribution of the article with the strict proviso that no changes or edits are made and the original work is properly cited (including links to both the formal publication through the relevant DOI and the license). See: https://creativecommons.org/licenses/by-nc-nd/4.0/.

\section{References}

1. Xu Q, Zhang H, Zhu YM, et al. Effects of Combined General/Epidural Anesthesia on Hemodynamics, Respiratory Function, and Stress Hormone Levels in Patients with Ovarian Neoplasm Undergoing Laparoscopy. Med Sci Monit 2016;22:4238-46.

2. Lee EJ, Kang H, Kim DH. A comparative study of laparoscopic radical hysterectomy with radical abdominal hysterectomy for early-stage cervical cancer: a longterm follow-up study. Eur J Obstet Gynecol Reprod Biol 2011;156:83-6.

3. Taylor SE, McBee WC Jr, Richard SD, et al. Radical hysterectomy for early stage cervical cancer: laparoscopy versus laparotomy. JSLS 2011;15:213-7.

4. Mastroyannis C, Hosoi Y, Yoshimura Y, et al. The effect of a carbon dioxide pneumoperitoneum on rabbit follicular oocytes and early embryonic development. Fertil Steril 1987;47:1025-30.

5. Donatsky AM, Bjerrum F, Gogenur I. Surgical techniques to minimize shoulder pain after laparoscopic cholecystectomy. A systematic review. Surg Endosc 2013;27:2275-82.

6. Yasir M, Mehta KS, Banday VH, et al. Evaluation of post operative shoulder tip pain in low pressure versus standard pressure pneumoperitoneum during laparoscopic cholecystectomy. Surgeon 2012;10:71-4.

7. Peng H, Zhang J, Cai C, et al. The Influence of Carbon Dioxide Pneumoperitoneum on Systemic Inflammatory Response Syndrome and Bacterial Translocation in Patients With Bacterial Peritonitis Caused by Acute Appendicitis. Surg Innov 2018;25:7-15.

8. Chen YZ, Xu YF, Zheng JH. Effect of carbon dioxide pneumoperitoneum on human renal cell carcinoma proliferation and metastasis in an orthotropic xenograft nude mouse model. Arch Med Sci 2014;10:1041-6.

9. Zhao S, Li W, Cheng F, et al. High-pressure carbon dioxide pneumoperitoneum induces oxidative stress and 
mitochondria-associated apoptotic pathway in rabbit kidneys with severe hydronephrosis. Int J Mol Med 2019;43:305-15.

10. Akdemir A, Taylan E, Sahin C, et al. The Impact of Carbon Dioxide Pneumoperitoneum on Ovarian Ischemia-Reperfusion Injury during Laparoscopic Surgery: A Preliminary Study. J Minim Invasive Gynecol 2018;25:638-43.

11. Giacobbe M, Mendes Pinto-Neto A, Simoes CostaPaiva LH, et al. The usefulness of ovarian volume, antral follicle count and age as predictors of menopausal status. Climacteric 2004;7:255-60.

12. Porembka MR, Hall BL, Hirbe M, et al. Quantitative weighting of postoperative complications based on the accordion severity grading system: demonstration of potential impact using the american college of surgeons national surgical quality improvement program. J Am Coll Surg 2010;210:286-98.

13. Critchley LA, Ho AM. Surgical emphysema as a cause of severe hypercapnia during laparoscopic surgery. Anaesth Intensive Care 2010;38:1094-100.

14. Kondo W, Bourdel N, Tamburro S, et al. Complications after surgery for deeply infiltrating pelvic endometriosis. BJOG 2011;118:292-8.

15. Menes T, Spivak H. Laparoscopy: searching for the proper insufflation gas. Surg Endosc 2000;14:1050-6.

16. Eleftheriadis E, Kotzampassi K, Papanotas K, et al. Gut ischemia, oxidative stress, and bacterial translocation in elevated abdominal pressure in rats. World J Surg 1996;20:11-6.

17. Marana E, Scambia G, Maussier ML, et al. Neuroendocrine stress response in patients undergoing benign ovarian cyst surgery by laparoscopy, minilaparotomy, and laparotomy. J Am Assoc Gynecol Laparosc 2003;10:159-65.

Cite this article as: Qin J, Song G, Jiang Y, Liu Q, Lin H. Low-pressure pneumoperitoneum reduces influence on ovarian hormones in infertile women. Ann Palliat Med 2021;10(5):5746-5753. doi: 10.21037/apm-21-476
18. Bogani G, Uccella S, Cromi A, et al. Low vs standard pneumoperitoneum pressure during laparoscopic hysterectomy: prospective randomized trial. J Minim Invasive Gynecol 2014;21:466-71.

19. Vinodh M, Mohankumar V, Ganpule A, et al. Does carbon dioxide pneumoperitoneum affect the renal function in donors following laparoscopic donor nephrectomy? A prospective study. J Minim Access Surg 2017;13:200-4.

20. Oosterhuis GJ, Vermes I, Michgelsen HW, et al. Follicle stimulating hormone measured in unextracted urine throughout the menstrual cycle correlates with age and ovarian reserve. Hum Reprod 2002;17:641-6.

21. McDougall EM, Monk TG, Wolf JS, Jr., et al. The effect of prolonged pneumoperitoneum on renal function in an animal model. J Am Coll Surg 1996;182:317-28.

22. Sayegh R, Garcia CR. Ovarian function after conservational ovarian surgery: a long-term follow-up study. Int J Gynaecol Obstet 1992;39:303-9.

23. Zhang X, Han T, Yan L, et al. Resumption of Ovarian Function After Ovarian Biopsy/Scratch in Patients With Premature Ovarian Insufficiency. Reprod Sci 2019;26:207-13.

24. Shah DK, Mejia RB, Lebovic DI. Effect of surgery for endometrioma on ovarian function. J Minim Invasive Gynecol 2014;21:203-9.

25. Araujo RSDC, Maia SB, Baracat CMF, et al. Ovarian function after the use of various hemostatic techniques during treatment for endometrioma: protocol for a randomized clinical trial. Trials 2019;20:410.

26. Spivak H, Nudelman I, Fuco V, et al. Laparoscopic extraperitoneal inguinal hernia repair with spinal anesthesia and nitrous oxide insufflation. Surg Endosc 1999;13:1026-9.

(English Language Editor: J. Jones) 